\title{
Contribuições do Modelo de Medição de Desempenho Organizacional da Performance Prism ao Balanced SCORECARD: UM ESTUDO SOB A PERSPECTIVA DOS STAKEHOLDERS
}

\author{
Contributions of Organizational Performance Measurement \\ Model Performance Prism to the Balanced Scorecard: a study \\ from the stakeholder's perspective
}

Sady Darcy da Silva Junior

Mestre em Administração e Negócios - PUCRS. Professor da Área de Administração. Instituto Federal de Educação, Ciência e Tecnologia do Rio Grande do Sul - Porto Alegre - RS - Brasil. E-mail: sady.junior@restinga.ifrs.edu.br

Edimara Mezzomo Luciano

Doutora em Administração - EA/UFRGS. Professora Titular da Faculdade de Administração, Contabilidade e Economia. Pontifícia Universidade Católica do Rio Grande do Sul - Porto Alegre - RS - Brasil.E-mail: eluciano@pucrs.br

Mauricio Gregianin Testa

Doutor em Administração - EA/UFRGS. Professor da Faculdade de Administração, Contabilidade e Economia. Pontifícia Universidade Católica do Rio Grande do Sul - Porto Alegre - RS - Brasil. E-mail: mauricio.testa@pucrs.br

\section{Resumo}

Medir o desempenho organizacional é um grande desafio para as empresas. Nesse sentido, merece destaque o Modelo de Medição de Desempenho Organizacional (MMDO) Balanced Scorecard (BSC). Entretanto, o modelo Performance Prism (PP) dá grande ênfase aos stakeholders organizacionais e afirma que o BSC trata-os de forma superficial, valorizando mais os acionistas (shareholders) e os clientes. Assim, o objetivo desta pesquisa é identificar as contribuições do PP ao BSC, sob a perspectiva dos stakeholders. Para isso, elaborou-se um roteiro semiestruturado de entrevistas que foi aplicado com profissionais da área de estratégia. Paralelamente, comparou-se a estrutura dos modelos visando enriquecer os resultados obtidos, além de complementar as análises das percepções dos entrevistados. Os resultados mostraram-se muito relevantes, visto que importantes contribuições identificadas do PP ao BSC contrapõem as próprias críticas originais do PP, que em grande parte se tornaram questionáveis por meio da percepção dos entrevistados e da comparação entre os modelos.

Palavras-chave: Performance Prism. Balanced Scorecard. Desempenho Organizacional. Estratégia. Stakeholders.

\section{Abstract}

Measuring the organizational performance is a big challenge to companies. Thus, we should highlight the organizational performance measurement model Balanced Scorecard (BSC). However, the Performance Prism (PP) model emphasizes the organizational stakeholders and states that BSC treats them in a superficial way, giving more importance to the shareholders and the customers. The objective of this research is to identify the PP contributions to the $\mathrm{BSC}$, from the stakeholders perspective. With this objective, a semi-structured script to the interviews was applied to professionals of the strategic area. In parallel, the structure of the models was compared to enrich the results, as well as to complement the analysis of the perceptions of respondents. The results were very relevant given important contributions of the $\mathrm{PP}$ to the BSC, opposing the original criticisms of the PP. These criticisms became questionable through the perception of respondents and the comparison between the models.

Keywords: Performance Prism. Balanced Scorecard. Organizational Performance. Strategy. Stakeholders. 


\section{INTRODUÇÃo}

Antes de iniciar o trabalho, os autores agradecem aos empresários, executivos e docentes que apoiaram esta pesquisa, sobretudo aos entrevistados, cujos nomes não podem ser revelados em função do acordo de sigilo estabelecido, sem os quais não seria possível a realização deste estudo.

Para Galas e Ponte (2005), é através da gestão estratégica que as organizações buscam garantir a manutenção de suas vantagens competitivas, dada a crescente instabilidade do ambiente no qual estão inseridas. No entanto, para os autores, os instrumentos de gestão estratégica baseados exclusivamente em indicadores contábeis e financeiros tornaram-se obsoletos. Além disso, Mintzberg e Quinn (2001) afirmam que boa parte do que foi publicado sobre estratégia, até a década de 1990, trata somente de como ela deve ser desenvolvida ou formulada.

No entanto, Marinho, Campos e Selig (2007) citam que a formulação e a implementação da estratégia organizacional são indissociáveis. Em função disso, atualmente vem crescendo, dentro da disciplina de gestão estratégica, a busca pelo conhecimento sobre a medição do desempenho organizacional, observando-se o surgimento de uma variedade de modelos para este propósito. Segundo Neely e Gregory (1995), a mensuração de desempenho pode ser definida literalmente como o processo de se quantificar uma ação, no qual mensuração é o processo de quantificação $e$ ação é aquilo que provoca o desempenho.

Reforçando essa ideia, Kaplan e Norton (2000) ressaltam que as empresas somente conseguem obter sucesso na implementação de suas estratégicas mediante o uso de um modelo de medição de desempenho organizacional (MMDO). Os autores afirmam ainda que, durante a fase de implementação das estratégias, a grande maioria das organizações encontra barreiras e dificuldades para colocá-las em ação, o que exige a adoção de eficientes MMDOs, visando à redução do risco de insucesso na busca dos objetivos estratégicos organizacionais.

Dentre os MMDOs desenvolvidos, merece destaque o Balanced Scorecard (BSC), proposto em 1992 por Robert Kaplan e David Norton. Os autores testemunham o crescimento e a prosperidade de várias organizações adeptas ao BSC, desde 1996.
Segundo eles, foram verificados resultados notáveis em empresas dos mais variados portes, industriais e de serviços, maduras e em rápido crescimento, dos setores público e privado, bem como com ou sem fins lucrativos (KAPLAN; NORTON, 2000). Soares Júnior e Prochnik (2004) reforçam o sucesso do modelo ao afirmarem que o BSC é um dos MMDOs mais utilizados pelas organizações.

Porém, apesar do sucesso que vem obtendo, o BSC sofre críticas quanto ao atendimento aos stakeholders organizacionais. Nesse aspecto, Norreklit (2000) e Schneiderman (1999) citam algumas limitações do $B S C$ :

a) necessidade de outras perspectivas para atender todos os stakeholders;

b) as variáveis independentes (não financeiras) são identificadas incorretamente como direcionadores primários da satisfação futura dos stakeholders;

c) falta de representatividade dos empregados na definição de objetivos e medidas estratégicas; $e$

d) ausência de avaliação criteriosa do ambiente externo.

Essas críticas tornam-se bastante relevantes, na medida em que ressaltam a importância dos stakeholders para as organizações. Freeman (1984) afirma que o conceito de stakeholder pode ser proveitoso se integrado a algumas questóes relacionadas à estratégia organizacional como, por exemplo, de que forma as organizações podem configurar a si próprias no sentido de executarem ações visando o alinhamento com o ambiente externo.

Em resposta a essas críticas, os próprios criadores do BSC reconhecem que o modelo incorpora, pelo menos explicitamente, somente os interesses de acionistas (shareholders) e clientes, não ficando claro, em uma análise superficial, o atendimento aos interesses dos demais stakeholders. Porém, eles afirmam que, na verdade, os interesses de todos os stakeholders podem ser incorporados ao BSC, citando como exemplo. (KAPLAN; NORTON, 1997):

a) Perspectiva dos funcionários: compõe praticamente todos os scorecards dentro da perspectiva do aprendizado e crescimento.

b) Perspectiva dos fornecedores: caso um forte relacionamento com os fornecedores faça 
parte da estratégia corporativa, até mesmo para obtenção de um desempenho superior sob a perspectiva dos clientes ou financeira, medidas associadas ao relacionamento com os fornecedores poderão ser incorporadas à perspectiva dos processos internos.

No entanto, em relação aos stakeholders destaca-se o MMDO Performance Prism (PP), que foi desenvolvido no Centre for Business Performance da Universidade de Cranfield (Inglaterra), cujo estudo foi liderado pelo pesquisador Andy Neely (NEELY; ADAMS; KENNERLY, 2002). A ideia por trás do modelo é que, apesar de existirem sistemas com medidas financeiras e não financeiras, como o próprio $B S C$, existia a necessidade de uma segunda geração de MMDOs, de forma a atender as organizações na atualização e/ou desenvolvimento de scorecards que sejam apropriados às demandas do ambiente competitivo de hoje, colocando os interesses dos stakeholders em primeiro plano.

Nesse contexto, para fins de obtenção do conhecimento necessário para o desenvolvimento deste estudo, o tema desta pesquisa são os MMDOs, com delimitação nos modelos BSC e PP, tendo como foco os stakeholders. Tendo em vista a delimitação do tema e o foco apresentado, a questão de pesquisa formulada é a seguinte: quais as contribuições do MMDO $P P$ ao $B S C$, sob a perspectiva dos stakeholders? Dessa forma, objetiva-se nesta pesquisa chegar à resposta da questão e, para tanto, este estudo foi organizado nas seguintes seções:

a) Referencial Teórico: estudo do conceito de stakeholders e dos MMDOs BSC e PP.

b) Método de Pesquisa: classificação do tipo de pesquisa, desenho de pesquisa, abordagem da construção do instrumento de pesquisa e da forma de coleta de dados, bem como da forma de análise dos dados e obtenção dos resultados.

c) Apresentação e Análise dos Resultados: apresentação dos principais resultados e interpretações, em função da análise dos pesquisadores.

d) Conclusões e Considerações Finais: conclusão dos resultados obtidos, cruzando-os com a questão e objetivo da pesquisa, limitações e sugestões para estudos futuros.

e) Referências: apresentação das referências que embasaram todo o estudo.

\section{Referencial Teórico}

O referencial teórico desta pesquisa está baseado no estudo do conceito de stakeholder e nos dois MMDOs em análise: BSC e PP. Convém ressaltar que, em função da pesquisa depender das estruturas originais dos dois modelos, o referencial deles baseia-se, em grande parte, nos textos originais elaborados pelos seus próprios criadores.

\subsection{Stakeholders}

Segundo Freeman (1984), o termo stakeholder teve sua primeira aparição na literatura de gestão em um memorando interno do Stanford Research Institute (atualmente SRI International Inc.), no ano de 1963. O termo servia para difundir a noção de stakeholder como o único grupo para quem os gestores devem oferecer respostas. Os pesquisadores do SRI demonstraram também que, a não ser que os executivos compreendessem as necessidades e interesses deste grupo, eles não poderiam formular objetivos corporativos que pudessem assegurar a sobrevivência da empresa, por falta do devido suporte necessário.

Dessa forma, o conceito foi originalmente definido como "[...] aqueles grupos de quem sem o suporte a empresa deixaria de existir" (FREEMAN, 1984, p. 31). No entanto, o mesmo autor define stakeholders, de uma forma mais atual do que o conceito de origem, como qualquer grupo ou indivíduo que pode afetar ou ser afetado pela realização dos objetivos da empresa, desempenhando um papel vital no sucesso de seus negócios. Já Gomes et al. (2010) ressaltam a importância das empresas considerarem as carências e aspirações dos stakeholders, até mesmo por uma questão de competitividade, produtividade e sustentabilidade organizacional. Para Costa (2005), a expressão stakeholder - sustentador, sustentáculo - é uma extensão ou generalização do conceito clássico de shareholder, que significa o acionista, o proprietário, o dono do negócio, traduzindo também a expressão como "partes interessadas". Nesse sentido, um stakeholder pode ser definido como

[...] qualquer instituição, pessoa, grupo de pessoas, formal ou informal, que tenha algum tipo de interesse que pode afetar ou ser afetado 
pelo funcionamento, operação, comercialização, desempenho, resultados presentes ou futuros da organização. (COSTA, 2005, p. 89)

Já para Thompson, Wartick e Smith (1991), stakeholder é qualquer ator, podendo ser uma pessoa, um grupo ou uma entidade, mas que tenha uma relação ou interesses, diretos ou insdiretos, com/ou sobre a organização.

No sentido de explicitar as definições, Freeman (1984) cita como stakeholders organizacionais representantes da comunidade local, proprietários/acionistas (shareholders), defensores do consumidor, consumidores, concorrentes, funcionários, grupos de interesses específicos, ambientalistas, fornecedores, governantes e mídia. Esses grupos de interesse ou indivíduos têm poder de influência crescente sobre a imprensa, poder executivo, opinião pública, mídia, órgãos e agências reguladoras e, principalmente, sobre o poder judiciário. Dessa forma, é cada vez mais importante conhecer, avaliar, considerar e tratar os stakeholders e seus interesses para a formulação da estratégia organizacional (COSTA, 2005). O autor afirma que a história está repleta de situações constrangedoras ou até mesmo catastróficas de empresas que simplesmente ignoraram os stakeholders e seus interesses, através de atitudes arrogantes ou autossuficientes, que resultaram em prejuízos financeiros e até mesmo de imagem.

Após a abordagem ao conceito e influência dos stakeholders nas organizações, a partir da próxima seção deste estudo serão abordados os MMDOs utilizados nesta pesquisa (BSC e PP).

\subsection{Balanced Scorecard (BSC)}

Em 1990, David Norton, CEO do Instituto Nolan Norton, juntamente com o consultor acadêmico Robert Kaplan, lideraram um estudo que tinha como objetivo desenvolver um novo MMDO (KAPLAN; NORTON, 1996). Os profissionais tinham a convicção de que as abordagens de medição de desempenho até então existentes estavam tornando-se obsoletas, uma vez que se apoiavam, principalmente, em medidas contábeis e financeiras. Como resultado desse estudo surgiu o $B S C$, cujo nome reflete o equilibrio fornecido entre os seguintes fatores (KAPLAN; NORTON, 1996): a) objetivos de curto e longo prazos;

b) medidas financeiras e não financeiras;

c) indicadores de ocorrências e de tendências; $e$

d) perspectivas de desempenho internas e externas.

Complementando o que foi exposto, Kaplan e Norton (1997) afirmam que o BSC é mais do que um sistema de medidas táticas ou operacionais, uma vez que empresas inovadoras estão utilizando o modelo, na verdade, como um sistema de gestão estratégica, para administrar a estratégia em longo prazo. Segundo os autores, o BSC complementa o planejamento da estratégia, pois traduz a missão e as estratégias da empresa em um conjunto abrangente de medidas de desempenho que serve de base para um sistema de medição e de gestão estratégica; o que permite o acompanhamento e a avaliação da implantação das estratégias em nível operacional. Complementando este ponto de vista dos autores do modelo, Oliveira et al. (2010) afirmam que o BSC, sendo conduzido pela alta administração, avalia a eficiência e a eficácia das estratégias implementadas, além de promover as condições necessárias para o alinhamento estratégico entre os diversos recursos e capacidades controlados pela empresa.

Isso, no entanto, é criticado por Souza, Ferreira e Gosling (2008), ao dizerem que no BSC o vínculo entre estratégia e operação pode não ser eficiente, principalmente em função da ausência de uma base histórica suficiente para análise dos indicadores, o que pode gerar conclusões imprecisas. No entanto, os criadores do BSC mantêm a convicção de que o modelo por eles criado, com o passar dos anos, evoluiu de uma eficiente ferramenta de mensuração de desempenho, originalmente introduzida por eles em 1992, para uma ferramenta de implementação de estratégias (KAPLAN; NORTON, 2004). Os autores ressaltam, inclusive, que essa mudança propiciou às organizações verem o BSC como um sistema de gerenciamento e de comunicação estratégica.

Para um melhor entendimento do modelo BSC, na próxima seção deste estudo será detalhada a sua estrutura. 


\subsubsection{Estrutura do BSC}

Para traduzir a visão e a estratégia em objetivos e medidas, o BSC é estruturado em quatro diferentes perspectivas, segundo Kaplan e Norton (1997):

a) Perspectiva Financeira: sintetiza as consequências econômicas imediatas das ações realizadas, através de medidas financeiras de desempenho, visto que são elas que indicam se a estratégia da empresa está contribuindo para a melhoria dos resultados do negócio, através de sua implementação e execução. Os autores propõem que os temas financeiros, tais como o aumento de receita e a melhoria em termos de custos e produtividade, servem de base para se definir as quatro perspectivas do BSC na grande maioria das organizações.

b) Perspectiva do Cliente: permite que os executivos identifiquem os segmentos de clientes e mercados nos quais a organização competirá, bem como as medidas de desempenho da organização nesses segmentos-alvo. Sendo assim, esta perspectiva deve incluir medidas específicas das propostas de valor que a empresa oferecerá aos clientes. Normalmente, as medidas básicas e genéricas do sucesso de uma estratégia bem formulada e implementada, como satisfação e retenção de clientes, encontram-se nesta perspectiva.

c) Perspectiva dos Processos Internos: existe para se identificar os processos internos críticos da organização, visando alcançar a sua excelência. As medições dessa perspectiva devem ser voltadas para os processos que têm maior impacto na atração, retenção e satisfação de clientes, em segmentos-alvo de mercado, bem como para o atendimento das expectativas dos shareholders atingindo, dessa forma, os objetivos financeiros da empresa.

d) Perspectiva do Aprendizado e Crescimento: identifica a infraestrutura que a empresa deve construir para que gere crescimento e melhorias no longo prazo. A ideia é que as empresas atinjam suas metas de longo prazo para clientes e processos internos, o que é improvável sem a utilização de novas tecnologias e capacidades. Kaplan e Norton (1997, p. 29) afirmam que "[...] o aprendizado e crescimento organizacionais provém de três fontes principais: pessoas, sistemas e procedimentos organizacionais".
A estrutura do BSC, partindo da visão e da estratégia organizacional e contemplando as quatro perspectivas já mencionadas, está representada graficamente na Figura 1:

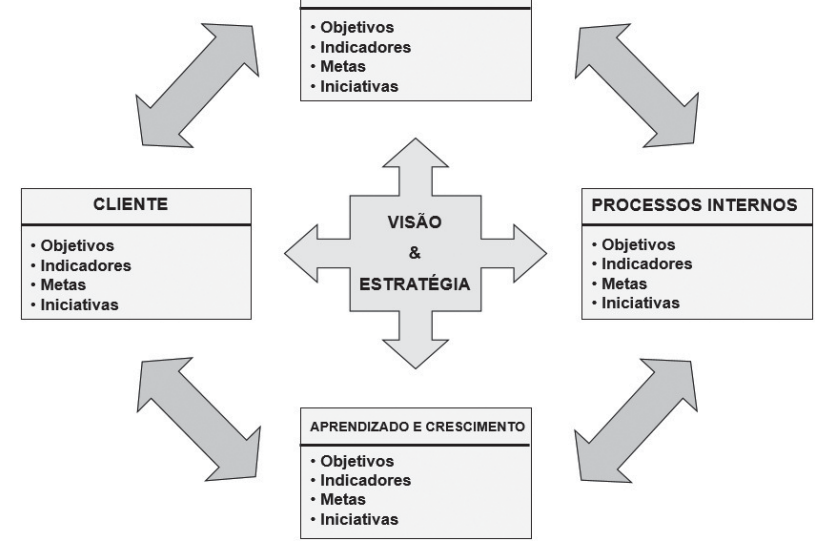

Figura 1: Estrutura do BSC para a tradução da estratégia em termos operacionais

Fonte: Adaptada de Kaplan e Norton (1997)

Muito embora as quatro perspectivas originais do BSC tenham se revelado suficientes em aplicações práticas, sendo adequadas em diversas empresas $e$ setores do mercado, esse modelo não deve se restringir ou se limitar a essas perspectivas (KAPLAN; NORTON, 1997). Os autores dizem que,

[...] não existe teorema matemático segundo o
qual as quatro perspectivas sejam necessárias
e suficientes. Ainda não encontramos empresas
que utilizem menos do que as quatro perspecti-
vas, porém, dependendo das circunstâncias, do
setor e estratégia de uma unidade de negócios,
é possível que seja preciso agregar uma ou
mais perspectivas complementares. (KAPLAN;
NORTON, 1997, p. 35)

Em relação aos objetivos, indicadores, metas e iniciativas do BSC, conforme se pode verificar na Figura 1, eles derivam da visão e da estratégia da empresa, sob o enfoque de cada uma das quatro perspectivas, $e$ este conjunto deve fornecer respostas a quatro questões básicas (KAPLAN; NORTON, 1997):

a) Para sermos mais bem-sucedidos financeiramente, como deveríamos ser vistos pelos nossos shareholders? (Perspectiva Financeira)

b) Para alcançarmos nossa visão, como deveríamos ser vistos pelos nossos clientes? (Perspectiva dos Clientes) 
c) Para satisfazermos nossos shareholders $e$ clientes, em que processos de negócio devemos alcançar a excelência? (Perspectiva dos Processos Internos)

d) Para alcançarmos nossa visão, como sustentaremos nossa capacidade de mudar e melhorar? (Perspectiva do Aprendizado e Crescimento)

No entanto, Del Carpio e Rocha-Pinto (2008) citam que a apuração de indicadores, as análises de desempenho e a estruturação de processos de negócio demandam esforço e tempo no BSC, e se as pessoas responsáveis por gerar os dados e acompanhar os projetos não enxergarem os benefícios deste esforço, perceberão o modelo como um trabalho adicional extraordinário ou, meramente, como mais uma ferramenta de controle.

Na próxima seção deste estudo será abordado o MMDO Performance Prism.

\subsection{Performance Prism (PP)}

O modelo PP foi desenvolvido no Centre for Business Performance, da Universidade de Cranfield (Inglaterra), liderado pelo pesquisador Andy Neely. O objetivo era integrar os melhores aspectos dos MMDOs, agregando as diferentes perspectivas de desempenho fornecidas por esses sistemas, além de colocar a visão dos stakeholders em primeiro plano.

Neely, Adams e Crowe (2001) argumentam que o principal motivador para a criação do $P P$ foi o fato de terem identificado que, apesar de existirem modelos com medidas financeiras e não financeiras, como o próprio $B S C$, por exemplo, existia a necessidade de uma segunda geração de MMDOs, de forma a atender as empresas na atualização e/ou desenvolvimento de scorecards que fossem apropriados às demandas do ambiente cada vez mais competitivo em que as organizações estão inseridas, com foco nos stakeholders.

Nesse contexto, o PP surgiu como um MMDO que coloca a visão dos stakeholders em primeiro plano, composto por cinco faces inter-relacionadas de um prisma (Figura 2):
a) satisfação do stakeholder;
b) estratégias;
c) processos;

d) capacidades; $e$

e) contribuição do stakeholder.

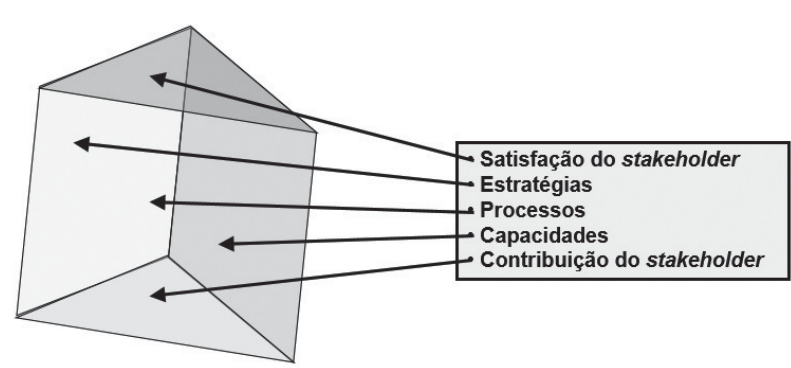

Figura 2: As cinco faces do Performance Prism

Fonte: Adaptada de Neely, Adams e Kennerly (2002)

Na visão de Neely, Adams e Kennerly (2002), no ambiente competitivo em que as organizações estão inseridas, existe a necessidade de se ter um quadro claro de quem são seus stakeholders e o que eles necessitam. Os autores também citam que as estratégias a serem seguidas pela organização devem ser definidas de forma a entregar valor a eles. Da mesma forma, os processos para conseguir implementar essas estratégias devem ser claramente definidos, bem como as capacidades necessárias para administrar e operar esses processos precisam ser desenvolvidas. Outro ponto fundamental é saber o que a organização quer dos seus stakeholders, além das medidas financeiras voltadas exclusivamente aos shareholders.

Em termos de medição de desempenho, uma das ideias mais erradas é a de que medidas de desempenho devem derivar da estratégia. Esta é uma forma incorreta de compreender o propósito da medição e o papel da estratégia (NEELY; ADAMS; CROWE, 2001). Para os autores, medidas de desempenho são feitas para ajudar os gerentes a saberem se o destino será alcançado, enquanto a estratégia representa o caminho escolhido para se chegar ao destino desejado. Com base nesses conceitos, o modelo PP ajuda a identificar as necessidades da empresa em termos de medidas de desempenho a serem adotadas, tentando responder às questões feitas para cada uma das suas cinco faces:

a) Quem são os stakeholders-chave e o que eles querem e precisam?

b) Quais estratégias a organização deve seguir para satisfazer o que os stakeholders querem e precisam? 
c) Quais processos são necessários para se atingir estas estratégias?

d) Quais capacidades são necessárias para operacionalizar e melhorar os processos identificados na questão anterior?

e) O que a empresa quer e precisa dos stakeholders, visando desenvolver e manter essas capacidades?

Na próxima seção serão detalhadas as cinco faces do $P P$.

\subsubsection{As Cinco Faces do Performance Prism}

Segundo os autores, a primeira face do prisma, a satisfação do stakeholder, tem uma abrangência maior do que a visão do stakeholder no BSC, visto que o enfoque vai além dos clientes e dos shareholders, englobando também funcionários, fornecedores, entidades regulatórias, comunidades locais etc., sustentando que todos podem ter um grande impacto no desempenho e sucesso de uma organização.

A segunda face do prisma concentra-se nas estratégias. Somente depois de se definir quem são os stakeholders, bem como o que eles querem e precisam, é possível pensar em estratégias que possam satisfazê-los. É na face da estratégia que se controla se os objetivos estão sendo cumpridos, além do fornecimento de informações para decisões executivas.

A terceira face compreende os processos gerais de negócio que permeiam as organizações, como o desenvolvimento de novos produtos e serviços, geração de demanda e planejamento e gerenciamento da empresa. Segundo os autores, é possível identificar medidas de desempenho específicas para cada um destes processos, de forma que a gerência possa verificar a sua eficiência e a eficácia, corrigindo-os quando necessário.

A quarta face do prisma, das capacidades, é a menos compreendida dentro do modelo (NEELY; ADAMS; CROWE, 2001). Os autores definem capacidade como uma combinação de pessoas certas, práticas corretas, tecnologia e infraestrutura adequadas que, juntas, facilitam a execução dos processos de negócio e dão suporte para a organização competir, afirmando ainda que, sem tudo isso, é impossível executar ou melhorar os processos.

A quinta e última face, a contribuição dos stakeholders, reconhece o fato de que não somente a organização deve entregar valor aos stakeholders, visto que eles também devem contribuir para a organização. O PP é o único MMDO que reconhece o relacionamento recíproco entre os stakeholders e a organização. (NEELY; ADAMS; CROWE, 2001)

Na próxima seção será demonstrado o método de pesquisa utilizado neste estudo.

\section{Método de Pesquisa}

Esta pesquisa é de natureza exploratória, a qual deve ser aplicada quando o objetivo é examinar um tema ou problema de investigação pouco estudado ou que não tenha sido abordado anteriormente (SAMPIERI; COLLADO; LUCIO, 1991). Segundo Mattar (1992), outro ponto que caracteriza o aspecto exploratório é o fato de ela procurar fornecer maiores conhecimentos sobre o tema e o foco de pesquisa, além de uma maior compreensão sobre o fenômeno em estudo.

Quanto aos dados coletados, esta pesquisa é qualitativa. A abordagem qualitativa é especialmente útil em situações que envolvem o desenvolvimento $e$ aperfeiçoamento de novas ideias, o que é aderente à proposta deste estudo, na medida em que se busca exatamente a complementaridade entre dois MMDOs existentes, aparentemente antagônicos.

Conforme Marconi e Lakatos (2003), uma vez tomada a decisão de realizar uma pesquisa, deve-se pensar na elaboração de um desenho que facilite o seu entendimento geral. Esse desenho possibilita ao pesquisador uma abordagem objetiva e confere uma ordem lógica ao trabalho. Sendo assim, o desenho de pesquisa deste estudo é apresentado na Figura 3: 
Questão de Pesquisa - Quais as contribuições do modelo de medição de desempenho organizacional Performance Prism ao Balanced Scorecard, sob a perspectiva dos stakeholders?

L L

Referencial Teórico - Stakeholders / Balanced Scorecard (BSC) / Performance Prism (PP)

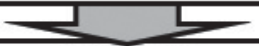

Preparação da Coleta - Definição das Dimensões e Variáveis / Elaboração do roteiro de entrevistas

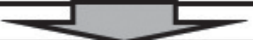

Coleta de Dados - Entrevistas com sete profissionais da área de estratégia (Gravadas e transcritas) L2

Análise dos Dados - Análise Comparativa da Estrutura dos Modelos BSC e PP - Análise das transcrições das entrevistas (Análise de Conteúdo - Avaliação)

Conclusões e Considerações Finais - Conclusões e considerações finais obtidas a partir da análise dos dados, acerca das contribuições do modelo PP ao BSC, sob a perspectiva dos stakeholders

Figura 3: Desenho de pesquisa

Fonte: Elaborada pelos autores deste artigo

A primeira etapa do desenho caracterizou-se pela definição da questão de pesquisa, conforme detalhado anteriormente na introdução deste estudo (Seção 1). Em seguida, foi desenvolvido o referencial teórico, que serviu de base para os passos posteriores, dividindo-o em três assuntos: Stakeholders, seguido dos MMDOs $P P$ e BSC.

A etapa seguinte da pesquisa tratou da preparação da coleta de dados, mais especificamente da criação de um roteiro semiestruturado de entrevista. Nesta etapa, visando apoiar a construção do instrumento de coleta de dados, optou-se por definir as dimensões e variáveis envolvidas neste estudo, onde as dimensões foram definidas conforme segue:

a) Stakeholders: a definição desta dimensão deu-se em função de tratar-se do foco desta pesquisa (Seção 1), que representa o primeiro bloco de estudo do referencial teórico.

b) Desempenho Organizacional: relacionado ao tema desta pesquisa (Seção 1), sendo o assunto que guiou o segundo e terceiro blocos de estudo do referencial teórico.

c) Perspectivas: apesar de não fazer parte explicitamente do tema nem do foco deste estudo, ao avaliar a questão de pesquisa e o referencial teórico, os autores verificaram que alguns questionamentos referentes diretamente às perspectivas do BSC seriam necessários. Sendo assim, foi considerada também essa dimensão neste estudo.

As variáveis da pesquisa foram definidas com base nas estruturas originais do $P P$ e do $B S C$, bem como nas críticas ao modelo BSC, principalmente em relação a sua abrangência no atendimento aos stakeholders organizacionais. No Quadro 1 são demonstradas as variáveis identificadas para cada uma das dimensões anteriormente citadas, além do código de cada uma das variáveis e dos autores que embasaram essas identificações, referenciados neste estudo. 
Sady Darcy da Silva Junior • Edimara Mezzomo Luciano • Mauricio Gregianin Testa

\begin{tabular}{|c|c|c|c|}
\hline Dimensão & VARIÁVEL & $\begin{array}{c}\text { Código } \\
\text { (Dim. X VAR.) }\end{array}$ & Autores \\
\hline \multirow{2}{*}{$\begin{array}{l}\text { Stakeholders } \\
\text { (D1) }\end{array}$} & Abrangência (V1) & D1V1 & $\begin{array}{l}\text { Freeman (1984); Costa (2005); Thompson, Wartick e Smith } \\
\text { (1991); Norreklit (2000); Schneiderman (1999); Kaplan e } \\
\text { Norton (1997); Neely, Adams e Kennerly (2002) }\end{array}$ \\
\hline & $\begin{array}{l}\text { Satisfação e } \\
\text { Contribuição (V2) }\end{array}$ & D1V2 & $\begin{array}{l}\text { Freeman (1984); Gomes et al. (2010); Costa (2005); Norreklit } \\
\text { (2000); Schneiderman (1999); Kaplan e Norton (1997); Neely, } \\
\text { Adams e Kennerly (2002); Neely, Adams e Crowe (2001) }\end{array}$ \\
\hline \multirow{3}{*}{$\begin{array}{l}\text { Desempenho } \\
\text { Organizacional } \\
\text { (D2) }\end{array}$} & $\begin{array}{l}\text { Operações, Produtos } \\
\text { e Serviços (V3) }\end{array}$ & D2V3 & $\begin{array}{l}\text { Souza, Ferreira e Gosling (2008); Del Carpio e Rocha-Pinto } \\
\text { (2008); Neely, Adams e Kennerly (2002); Neely, Adams e } \\
\text { Crowe (2001) }\end{array}$ \\
\hline & $\begin{array}{l}\text { Processos e } \\
\text { Capacidades (V4) }\end{array}$ & D2V4 & $\begin{array}{l}\text { Del Carpio e Rocha-Pinto (2008); Kaplan e Norton (1997); } \\
\text { Oliveira, Gonçalves e de Paula (2010); Neely, Adams e Crowe } \\
\text { (2001) }\end{array}$ \\
\hline & $\begin{array}{l}\text { Estrutura } \\
\text { Organizacional (V5) }\end{array}$ & $\mathrm{D} 2 \mathrm{~V} 5$ & \multirow{4}{*}{ Kaplan e Norton (1997); Neely, Adams e Crowe (2001) } \\
\hline \multirow{3}{*}{$\begin{array}{l}\text { Perspectivas } \\
\text { (D3) }\end{array}$} & Sinergia e Cultura (V6) & D3V6 & \\
\hline & Capacidades (V7) & D3V7 & \\
\hline & Gestão e Inovação (V8) & D3V8 & \\
\hline
\end{tabular}

Quadro 1: Dimensões e variáveis da pesquisa

Fonte: Elaborado pelos autores deste artigo

Convém ressaltar que o "Código (Dim. X Var.)" do Quadro 1 é proveniente da combinação do código da dimensão com o código da variável.

A partir do referencial teórico e das orientações de Cooper e Schindler (2003), criou-se um roteiro semies- truturado de entrevista com questões para cada uma das combinações de dimensão x variável demonstradas no Quadro 1, utilizando o "Código Dim. X Var" para demonstrar as relações entre as questões e respectivas combinações (Quadro 2):

\begin{tabular}{|c|c|}
\hline \multicolumn{2}{|c|}{$\begin{array}{l}\text { Código } \\
\text { (Dim. X VAR.) }\end{array}$} \\
\hline \multirow{2}{*}{ D1V1 } & $\begin{array}{l}\text { Questão 01: Que stakeholders o BSC abrange diretamente dentro das suas quatro perspectivas originais (Financeira/ } \\
\text { Clientes/Processos Internos/Aprendizado e Crescimento)? }\end{array}$ \\
\hline & $\begin{array}{l}\text { Questão 02: Que outros tipos de stakeholders poderiam ser contemplados no BSC? (Se for necessário citar: funcionários, } \\
\text { fornecedores e comunidade, por exemplo) }\end{array}$ \\
\hline \multirow{2}{*}{ D1V2 } & Questão 03: Como o BSC trata o atendimento às necessidades dos stakeholders? \\
\hline & Questão 04: Como o BSC transmite aos stakeholders o que a empresa necessita deles? \\
\hline D2V3 & $\begin{array}{l}\text { Questão 05: Como o BSC trata a questão do desdobramento da estratégia do nível corporativo para unidades de } \\
\text { negócio, considerando operações, produtos e serviços? }\end{array}$ \\
\hline D2V4 & $\begin{array}{l}\text { Questão 06: Como funciona, no BSC, o desdobramento das estratégias em relação aos processos necessários para } \\
\text { o atendimento das mesmas, bem como às capacidades necessárias para a execução desses processos? }\end{array}$ \\
\hline D2V5 & $\begin{array}{l}\text { Questão 07: Como você avalia a questão de busca de sinergias, alinhamento de cultura e redução de custos dentro } \\
\text { da estrutura interna da empresa, em relação aos seus departamentos e áreas funcionais? }\end{array}$ \\
\hline D3V6 & $\begin{array}{l}\text { Questão 08: Em relação à questão anterior, de que forma o retorno financeiro advindo desta busca de sinergia e } \\
\text { alinhamento de cultura pode ser enquadrado em alguma perspectiva do } B S C \text { ? }\end{array}$ \\
\hline D3V7 & $\begin{array}{l}\text { Questão 09: Onde se enquadram os ativos intangíveis organizacionais, como pessoas, práticas, tecnologia e } \\
\text { infraestrutura, em relação às perspectivas do } B S C \text { ? }\end{array}$ \\
\hline D3V8 & $\begin{array}{l}\text { Questão 10: Onde se enquadram características como desenvolvimento de produtos e serviços e gestão de demandas } \\
\text { e operações, em relação às perspectivas do BSC? }\end{array}$ \\
\hline
\end{tabular}

Quadro 2: Roteiro semiestruturado de entrevista

Fonte: Elaborado pelos autores deste artigo 
Convém ressaltar que o roteiro foi elaborado de forma a deixar transparente aos entrevistados o conhecimento do modelo $P P$, que é pouco difundido no Brasil. Ao mesmo tempo, teve-se a preocupação de que as respostas dos entrevistados permitissem alcançar o objetivo deste estudo. Para que isso fosse possível, as perguntas foram criadas contemplando as características do $P P$, buscando descobrir se elas existiam ou não no $B S C$, na percepção dos entrevistados.

Em seguida foi realizada a etapa da coleta de dados. Nessa fase, as entrevistas foram realizadas, gravadas (com autorização dos entrevistados) e transcritas. O roteiro de entrevistas foi aplicado com sete profissionais que atuam na área de estratégia organizacional, seguindo a premissa de que todos conhecessem o modelo BSC, cujos perfis constam no Quadro 3.

\begin{tabular}{|c|c|c|}
\hline $\begin{array}{l}\text { ENTREVIS- } \\
\text { TADO }\end{array}$ & Profissão & $\begin{array}{c}\text { CONHECIMENTO/ } \\
\text { EstrAtÉGIA }\end{array}$ \\
\hline $\begin{array}{l}\text { Entrevistado } \\
1 \\
(\mathrm{E} 1)\end{array}$ & $\begin{array}{l}\text { Consultor organizacional } \\
\text { na área de estratégia e } \\
\text { Professor Universitário/ } \\
\text { Mestre em Administração/ } \\
\text { Gestão Estratégica }\end{array}$ & $\begin{array}{l}\text { Formulação e } \\
\text { implementação da } \\
\text { estratégia/BSC }\end{array}$ \\
\hline $\begin{array}{l}\text { Entrevistado } \\
2 \\
\text { (E2) }\end{array}$ & $\begin{array}{l}\text { Professor Universitário } \\
\text { de Estratégia - Doutor } \\
\text { em Administração/ } \\
\text { Gestão Estratégica }\end{array}$ & $\begin{array}{l}\text { Formulação e } \\
\text { implementação da } \\
\text { estratégia/BSC e } \\
\text { Performance Prism }\end{array}$ \\
\hline $\begin{array}{l}\text { Entrevistado } \\
3 \\
\text { (E3) }\end{array}$ & $\begin{array}{l}\text { Gerente corporativo } \\
\text { de uma empresa } \\
\text { multinacional, ligado } \\
\text { à estratégia }\end{array}$ & $\begin{array}{l}\text { Implementação da } \\
\text { estratégia/BSC }\end{array}$ \\
\hline $\begin{array}{l}\text { Entrevistado } \\
4 \\
\text { (E4) }\end{array}$ & $\begin{array}{l}\text { Diretor de Operações de } \\
\text { uma empresa na área de } \\
\text { Tecnologia da Informação }\end{array}$ & $\begin{array}{l}\text { Formulação e } \\
\text { implementação da } \\
\text { estratégia/BSC }\end{array}$ \\
\hline $\begin{array}{l}\text { Entrevistado } \\
5 \\
\text { (E5) }\end{array}$ & $\begin{array}{l}\text { Diretor de uma } \\
\text { Instituição Financeira } \\
\text { de Grande Porte }\end{array}$ & $\begin{array}{l}\text { Formulação e } \\
\text { implementação da } \\
\text { estratégia/BSC }\end{array}$ \\
\hline $\begin{array}{l}\text { Entrevistado } \\
6 \\
\text { (E6) }\end{array}$ & $\begin{array}{l}\text { Sócio-proprietário } \\
\text { de uma rede de lojas } \\
\text { no setor varejista }\end{array}$ & $\begin{array}{l}\text { Formulação e } \\
\text { implementação da } \\
\text { estratégia/BSC }\end{array}$ \\
\hline $\begin{array}{l}\text { Entrevistado } \\
7 \\
\text { (E7) }\end{array}$ & $\begin{array}{l}\text { Proprietário de uma rede } \\
\text { de franquias na área de } \\
\text { Tecnologia da Informação }\end{array}$ & $\begin{array}{l}\text { Formulação e } \\
\text { implementação da } \\
\text { estratégia/BSC }\end{array}$ \\
\hline
\end{tabular}

Quadro 3: Perfil dos entrevistados

Fonte: Elaborado pelos autores deste artigo

O processo de solicitação de participação dos entrevistados se deu por meio de contato telefônico e/ou por e-mail, explicando o objetivo e o escopo da entrevista. Os pesquisadores ofereceram-se para ir ao encontro dos profissionais, onde lhes fosse mais conveniente, solicitando a disponibilidade de horário deles e informando que a entrevista levaria aproximadamente trinta minutos, bem como que suas identidades seriam mantidas em sigilo.

Na etapa seguinte, de análise dos dados, foi utilizada a técnica de análise de conteúdo do tipo avaliação que, além de se ater à presença ou à ausência de determinados temas, como ocorre na análise de conteúdo temática, permite uma carga de análise de significação dos dados (BARDIN, 1995). A análise das entrevistas foi realizada em cinco fases, conforme segue:

1. organização: momento em que ocorreu a organização das gravações das entrevistas para a transcrição;

2. transcrição das entrevistas: transcrição das gravações das entrevistas;

3. leitura flutuante: busca de conhecimento preliminar do texto;

4. exploração do material: ocorreu a lapidação dos dados brutos para obter a compreensão do texto, de uma forma mais precisa, orientando-se pela metodologia definida; $e$

5. tratamento dos resultados: inferência e interpretação dos resultados.

Na próxima seção apresenta-se a análise dos resultados obtidos.

\section{Apresentação e Análise dos Resultados}

A apresentação e a análise dos resultados desta pesquisa foram divididas em dois blocos, um referente às impressões dos autores em relação ao referencial teórico, mais especificamente em termos de comparação das estruturas dos modelos $P P$ e BSC, e outro referente à análise das entrevistas com os sete especialistas. $\mathrm{Na}$ próxima seção será demonstrada a análise comparativa da estrutura dos dois modelos, realizada pelos autores.

\subsection{Análise Comparativa da Estrutura dos Modelos PP e BSC}

Chamou atenção dos autores, na análise das estruturas dos modelos PP e BSC, a partir do referencial 
teórico, a similaridade das faces do modelo $P P$ com as perspectivas do BSC, conforme demonstrado a seguir:

a) Primeira face do PP - Satisfação do Stakeholder: possui relação com as perspectivas $\mathrm{Fi}$ nanceira e de Clientes do BSC. No entanto, destaca o fato de considerar, explicitamente, os funcionários, fornecedores, entidades regulatórias, comunidades locais, etc. Nesse sentido, conforme citado na Seção 1 deste estudo, o BSC pode considerar outros stakeholders, além das perspectivas: Financeira ou de Clientes, de forma implícita, porém efetiva, conforme a necessidade da organização.

b) Segunda face do $P P$ - Estratégias: coloca a estratégia em segundo plano, depois de definir quem são os stakeholders, o que eles querem e precisam. A diferença para o BSC é que nele a estratégia formulada fica em primeiro plano e, a partir dessa estratégia, se parte para a construção do modelo.

c) Terceira face do $P P$ - Processos: similar, em termos conceituais, à perspectiva de Processos Internos do BSC.

d) Quarta face do PP - Capacidades: similar, em termos conceituais, à perspectiva de Aprendizado e Crescimento do BSC.

e) Quinta face do PP - Contribuição do Stakeholder: a partir do referencial teórico, aparentemente é a única face que realmente acrescenta algo de diferencial em relação à estrutura original do BSC.

Chamou também a atenção dos pesquisadores, desconsiderando o posicionamento distinto das estratégias e o aspecto referente à contribuição do stakeholder, aparentemente ausente na estrutura original do $B S C$, certa similaridade em relação à ordem sugerida para as perspectivas do BSC e para as faces do $P P$, conforme pode ser observado na Figura 4, que sintetiza a análise comparativa da estrutura dos dois modelos, realizada nesta seção do estudo:

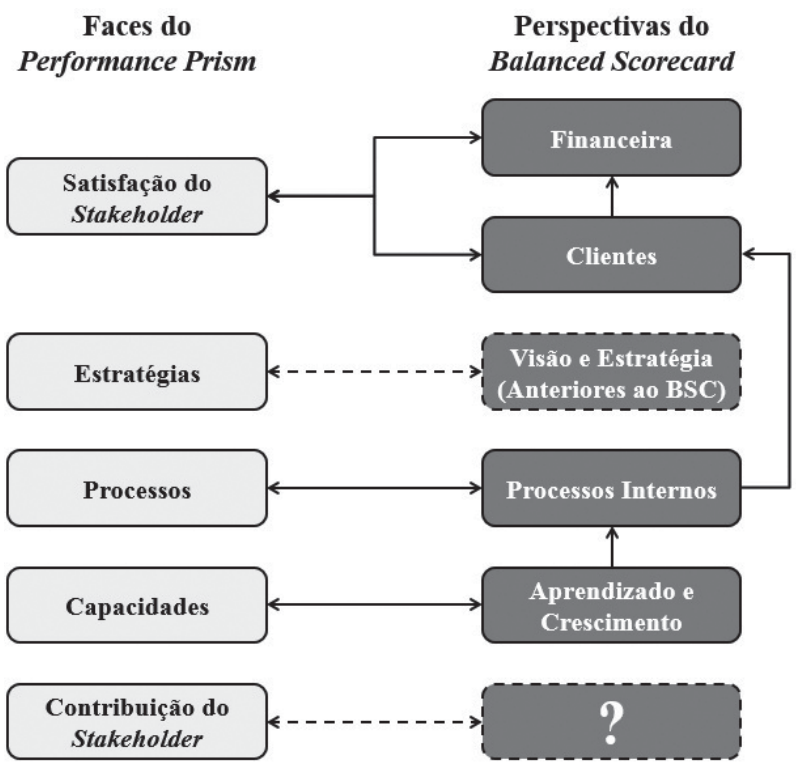

Figura 4: Análise Comparativa da Estrutura dos MMDOs $P P$ e BSC

Fonte: Elaborada pelos autores deste artigo

Na próxima seção será abordada a análise das transcrições das entrevistas com os sete profissionais da área de estratégia.

\subsection{Análise das Entrevistas com os Profissionais da Área de Estratégia}

Conforme dito anteriormente, nos procedimentos metodológicos desta pesquisa (Seção 3), os pesquisadores analisaram as transcrições das entrevistas realizadas com os sete profissionais envolvidos com estratégia organizacional, utilizando como técnica a análise de conteúdo, do tipo de avaliação (BARDIN, 1995). Como resultado dessa atividade, a análise de cada questão é demonstrada nos parágrafos seguintes.

A primeira questão referia-se a que stakeholders o BSC abrange diretamente, dentro das suas quatro perspectivas. Nesse sentido, os entrevistados 1, 2, 3 e 5 consideram que existe uma interligação entre todas as perspectivas e todos os stakeholders organizacionais, não cabendo uma avaliação isolada, como afirma, por exemplo, o entrevistado 1: "[...] na realidade, os stakeholders envolvidos acabam influenciando, praticamente, em todas as dimensões [...]", e o entrevistado 5, ao dizer que "[...] não tem como executar a estratégia da empresa sem considerar, direta ou indiretamente, qualquer tipo de stakeholder". Os entrevistados 4, 6 e 7 avaliam de outra forma, salientando que qualquer 
tipo de stakeholder pode ser enquadrado no BSC, se não dentro das quatro perspectivas padrão, através de perspectivas criadas especificamente para esse fim, já que os próprios autores do modelo sugerem isso. Dessa forma, verificou-se que o BSC, da mesma forma que o $P P$, pode atender a uma gama de stakeholders maior do que sugerem explicitamente as suas perspectivas originais.

Sobre a segunda questão, se outros tipos de stakeholders poderiam ser contemplados no BSC, os entrevistados 1, 2 e 5 consideram que os stakeholders, de um modo geral, são tratados implicitamente no planejamento estratégico definido anteriormente ao BSC, na definição de forças, fraquezas, oportunidades e ameaças, por exemplo. Merece destaque o entrevistado 2 , que citou, utilizando como exemplo os fornecedores, que "[...] o BSC não tem na teoria coisas específicas para fornecedores, mas é possível se mapear". Já o entrevistado 3 não consegue enxergar isso claramente, baseando-se na forma como a empresa em que trabalha utiliza o BSC, enquanto os entrevistados 4, 6 e 7 reforçaram os seus posicionamentos da primeira questão, respondendo afirmativamente, a respeito do enquadramento ou criação de novas perspectivas, se necessário. Com isso, da mesma forma que na questão 1 , verificou-se uma percepção positiva dos entrevistados em relação à possibilidade de atendimento a outros tipos de stakeholders no BSC. Porém, chamou a atenção o fato de o entrevistado 3, apesar de acreditar nessa possibilidade, com base em sua resposta na primeira questão, não enxergar isso com clareza em função da forma como a empresa em que trabalha utiliza o BSC.

A terceira questão tratava se o BSC é focado no atendimento das necessidades dos stakeholders. Os entrevistados 1 e 5 consideram que o BSC traduz os objetivos e interesses, primeiramente, da organização, dos shareholders, e não necessariamente a visão dos demais stakeholders, embora isso esteja subentendido nos interesses da organização. Esse posicionamento é semelhante ao dos entrevistados 2, 4 e 7, que acreditam que isso é mais verdadeiro na perspectiva financeira, em relação aos interesses dos acionistas, do que nas demais perspectivas, que buscam atendimento às necessidades dos demais stakeholders, porém de forma menos efetiva. Já o entrevistado 6 acredita que exista um equilíbrio, ao citar que "[...] se o BSC for usado como deve ser, naturalmente se acabará atendendo as necessidades dos stakeholders organizacionais, claro que isso depende da importância que cada tipo de stakeholder tiver para a empresa". O entrevistado 3, por sua vez, considera que,

[...] é muito clara cada etapa. No momento que tu tem certeza que tu sabe, e é claro pra ti o que os stakeholders estão esperando, é mais fácil tu atender teus clientes, modelar os teus processos, tu conduzir a empresa pra receber aquele retorno financeiro que os acionistas querem, então eu acho que contribui bastante.

Como se pode notar, do ponto de vista dos entrevistados, apesar do possível equilíbrio pressuposto pelo entrevistado 6, ficou evidente um viés de atendimento às necessidades dos shareholders da organização, acima dos demais stakeholders.

A quarta questão era sobre se o BSC transmite aos stakeholders o que a empresa necessita deles. Nesse sentido, todos os entrevistados responderam afirmativamente. Destacam-se as respostas dos entrevistados 1 , que, conforme citou na terceira questão, considera que o BSC traduz, primeiramente, os objetivos e interesses da organização, e, dessa forma, acaba por focar no que a empresa necessita de seus stakeholders, e do entrevistado 3, que afirmou que "[...] tendo bem claro os pontos principais que tu quer chegar, para todos, daqui a um ano, dois, eu acho que o BSC contribui sim neste sentido". O entrevistado 7, apesar de considerar que é possível, salientou que "[...] depende de que tipo de stakeholder: se for relativo aos que dependem mais da empresa, como funcionários, acionistas e fornecedores, acho que sim; mas se forem stakeholders mais externos, como clientes, governo $e$ comunidade em geral, acho mais difícil". Com isso, verificou-se de forma unanime entre os entrevistados que o argumento do $P P$ de que é necessário se definir as contribuições dos stakeholders é verificado no BSC, com ressalva à consideração do entrevistado 7 .

Em relação à quinta questão, sobre o desdobramento da estratégia do nível corporativo para as unidades de negócio, considerando operações, produtos e serviços, através do BSC, apenas o entrevistado 3 enxerga isso com clareza. Os demais entrevistados consideram que existe certa dificuldade neste desdobramento, sendo que ele tende a ser mais trabalhado em nível corporativo, de forma geral, salientando que na teoria esse processo é bem mais fácil do que na 
prática. Merece destaque a resposta do entrevistado 1 , que afirmou que "[...] esse detalhamento, desdobramento, ele vai acontecer não no desenho do BSC, mas sim nas implementações das ações necessárias para este desdobramento". Dessa forma verificou-se que, na prática, o desdobramento sugerido pela teoria é de difícil realização e que, às vezes, as empresas confundem as intenções descritas no modelo com a realidade praticada.

Ao serem questionados sobre como funciona. no BSC, o desdobramento da estratégia em termos de processos e capacidades, referente à sexta questão desta pesquisa, as opinióes foram um tanto quanto distintas, com ideias contrárias e ponderações. O entrevistado 1 acredita que isso não ocorre, visto que o BSC é muito mais focado nos objetivos do que nos meios que a empresa vai precisar para fazer isso acontecer, ficando isso muito mais para os planos de ação posteriores que deverão ser realizados. Esse ponto de vista é inverso ao dos entrevistados 2 e 6 , que acreditam que isso se dá exatamente na relação que o BSC tem com a estratégia formulada anteriormente, servindo ele de auxiliar no desdobramento dessa estratégia, exatamente por meio das ações e projetos que serão executados a partir dos objetivos definidos dentro das quatro perspectivas. O entrevistado 3 também acredita que isso ocorre no BSC, em função de um melhor entendimento dos processos por todos, o que também foi considerado pelo entrevistado 7, e da maior eficácia na comunicação das estratégias, enquanto o entrevistado 5 cita que "este é um processo natural no BSC, pois se parte das capacidades no aprendizado e crescimento diretamente para os processos de negócio que serão sustentados por estas capacidades". Já o entrevistado 4 acredita que pode ser possível este desdobramento, porém ponderando que, "[...] do meu ponto de vista, este tipo de desdobramento não se dá exatamente dentro do BSC em si, mas através da cultura da empresa voltada para isso, através da crença de seus proprietários e acionistas, principalmente."

Com exceção do entrevistado 1 , verificou-se este desdobramento como possível dentro do BSC, seja por meio das ações e projetos sugeridos, seja pela melhoria na comunicação da estratégia e no entendimento dos processos. No entanto, conforme foi visto, essa possibilidade envolve também aspectos de cultura $e$ crença organizacional que, de certa forma, até podem sugerir que isso aconteça fora dos domínios do BSC, conforme citou o entrevistado 4.

A respeito da sétima questão, referente à busca de sinergias, alinhamento de cultura e redução de custos na estrutura interna da organização, as respostas foram muito distintas. O entrevistado 1 não enxerga isso, dizendo que "[...] nos casos que eu tenho vivenciado, se existe, é fraco, porque geralmente o que está muito mais por trás é a parte do interesse econômico, financeiro e corporativo". O entrevistado 2 acredita que, dentro das organizações, este processo é cultural e, por esse motivo, lento e gradativo. Quanto ao BSC, o entrevistado citou que ele pode auxiliar neste sentido, na medida em que possibilita a comunicação das estratégias e, consequentemente, apoia o alinhamento entre as áreas funcionais. Os entrevistados 3 e 5 consideram ser possível esta busca de sinergia e alinhamento dentro da empresa. Vale ressaltar a resposta do entrevistado 3 , ao considerar que

[...] não chega ao nível de um processo de fusão ou aquisição, por exemplo, que já prevê inicialmente uma fusão de cultura, processos e estrutura de custos, com esta busca dentro de uma organização, onde normalmente cada departamento acaba funcionando como uma ilha, com sua cultura e objetivos próprios, onde não se pode forçar tanto para que as coisas aconteçam.

Os entrevistados 4 e 7 acham que isso ocorre bem aquém do que deveria nas empresas, salientando que existem muitas falhas e deficiências por parte das organizações, nesse sentido, enquanto o entrevistado 6 salientou que "[...] na teoria isso parece muito mais fácil do que na prática, onde o que se vê são as áreas da empresa disputando por recursos e defendendo interesses próprios". Com isso verificou-se, de uma forma geral, uma grande dificuldade no sentido de se buscar na estrutura interna organizacional, entre suas áreas e departamentos, sinergias, alinhamento de cultura e redução de custos, tal qual se esperava que acontecesse.

A oitava questão tratava da forma de enquadramento no BSC do retorno financeiro advindo da busca de sinergia e alinhamento de cultura, abordados na questão anterior. Com exceção de um entrevistado, todos os demais citaram que isso se dá dentro da perspectiva financeira, visto que ela ressalta, naturalmente, 
a importância dos resultados financeiros a partir das ações realizadas pela empresa e da racionalização de sua estrutura. O entrevistado 3 discorda desta opinião ao entender que o enquadramento deste retorno se dá nas perspectivas de aprendizado e crescimento, na medida em que as pessoas estariam mais preparadas para desenvolver os processos e funções para os quais foram contratadas, e na de processos internos, na medida em que, nesta busca de sinergia e alinhamento,

[...] por mais que tu tenha certeza que tu tenha visto e avaliado a eficiência dos processos, sempre tem que olhar de novo, porque as vezes os processos se perdem no meio do caminho, e as pessoas acabam colocando o seu jeito, o que nem sempre é o melhor, nem sempre é o mais eficiente em termos de processos.

Com isso, ficou evidenciado o enfoque do enquadramento do retorno com a busca de sinergia $e$ alinhamento de cultura na perspectiva financeira, em termos gerais, com possibilidade de enquadramento em outras perspectivas, em termos específicos.

Quanto ao enquadramento dos ativos intangíveis organizacionais nas perspectivas do BSC, nona questão do roteiro, todos os entrevistados foram unânimes no enquadramento destes ativos na perspectiva do aprendizado e crescimento. No entanto, os entrevistados 1 e 2 destacaram também o enquadramento dos ativos na perspectiva dos processos internos, com destaque a um comentário do entrevistado 2 , dizendo que "[...] infraestrutura e tecnologia, por serem mais ligadas a atividades de apoio, talvez fiquem com um papel mais secundário nos objetivos estratégicos da empresa". Já o entrevistado 5 enquadrou os ativos intangíveis também na perspectiva dos clientes, uma vez que "[...] muitas vezes, a marca da empresa perante os clientes ou até mesmo a sua carteira de clientes caracterizam-se como os seus maiores ativos intangíveis". Como era de se esperar, dado o conhecimento dos entrevistados do modelo BSC, o enquadramento de ativos organizacionais intangíveis se deu essencialmente na perspectiva do aprendizado e crescimento, além de algumas opiniões nas perspectivas de processos internos e clientes.

A décima e última questão do roteiro abordou o enquadramento de desenvolvimento de produtos, serviços e gestão de demandas e operações nas perspectivas do BSC. Todos os entrevistados foram unânimes em relação ao enquadramento destes aspectos dentro da perspectiva dos processos internos. No entanto, os entrevistados 2 e 7 salientaram que o desenvolvimento de serviços inovadores pode também ser enquadrado na perspectiva dos clientes, uma vez que, conforme o entrevistado 7, " [...] muitas vezes as empresas identificam produtos ou serviços inovadores a partir das expectativas dos clientes". Já os entrevistados 3 e 5 citaram que enxergam o desenvolvimento de produtos e serviços também dentro da perspectiva de aprendizado e crescimento. Como pode ser observado, conforme as respostas dos entrevistados, o BSC engloba, principalmente dentro da perspectiva dos processos internos, o desenvolvimento de produtos e serviços, além da gestão de demandas e operações, apesar de essas questões poderem também ser enquadradas em outras perspectivas.

Para fins de um bom entendimento dos resultados apresentados até o momento nesta seção da pesquisa, foi criado um resumo da análise das entrevistas com os profissionais da área de estratégia (Quadro 4): 


\section{QUESTÃo}

Opinião

Entrevistado (s)

QUESTÃo 01 - QUE STAKEHOLdeRS O BSC ABRANGE DIRETAMENTE DENTRO DAS SUAS QUATRO PERSPECTIVAS?

Existe uma interligação entre todas as perspectivas e todos os stakeholders organizacionais

Qualquer tipo de stakeholder pode ser enquadrado no BSC (criação de novas perspectivas)

$\mathrm{E} 4 / \mathrm{E} 6 / \mathrm{E} 7$

Questão 02: Que OUTROS TIPOS DE STAKEHOLDERS PODERIAM SER CONTEMPLADOS No BSC?

Os stakeholders são tratados implicitamente no Planejamento Estratégico anterior ao BSC

$\mathrm{E} 1 / \mathrm{E} 2 / \mathrm{E} 5$

Não conseguiu responder com clareza, visto que não enxerga isso ocorrendo na prática

Qualquer tipo, senão nas perspectivas originais, criando-se novas perspectivas

E3

$\mathrm{E} 4 / \mathrm{E} 6 / \mathrm{E} 7$

Questão 03: COMO o BSC TRATA O ATENDIMENTO Às NECESSIDAdES DOS STAKEHOLDERS?

Atende os interesses dos shareholders (acionistas), não dos demais

E1/E5

Atende interesses além dos shareholders, porém de forma menos efetiva do que estes

$\mathrm{E} 2 / \mathrm{E} 4 / \mathrm{E} 7$

Atende com base na estrutura padrão (Processos èClientesèFinanceira (shareholders)

Pode existir um equilibrio no atendimento de interesses de todos os stakeholders

E6

Questão 04: CoMo o BSC TRANSMITE AOS STAKEHOLDERS O QUE A EMPRESA NECESSITA DELES?

Na medida em que se define e busca os objetivos organizacionais, isso se dá ao natural Todos

Depende do tipo de stakeholder - mais fácil para os que "dependem" da empresa

E7 (ressalva)

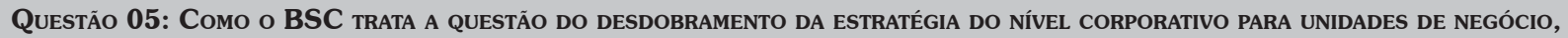
CONSIDERANDO OPERAÇÕES, PRODUTOS E SERVIÇOS?

De forma clara, natural E3

Enxergam dificuldade neste desdobramento, funcionando bem na teoria, não na prática Todos menos E3

O desdobramento acontece não no desenho do BSC, mas nas ações realizadas para isso

E1 (ressalva)

QUESTÃo 06: COMO FUnCIONA No BSC O DESDOBRAMENTO DA ESTRATÉGIA EM RELAÇÃo AOS PROCESSOS NECESSÁRIOS PARA O ATENDIMENTO DA MESMA, BEM COMO ÀS CAPACIDADES NECESSÁRIAS PARA A EXECUÇÃo DESTES PROCESSOS?

Isso não ocorre, visto que no BSC a preocupação é com os objetivos, e não com os meios E1

Isso se dá exatamente na relação que o BSC tem com a estratégia formulada anteriormente

Ocorre em função de um melhor entendimento por todos E2/E6

Ocorre através da maior eficácia na comunicação das estratégias

Isso ocorre ao natural, na medida que as capacidades sustentam os processos de negócio E3

Esse desdobramento não se dá dentro do BSC, mas através da cultura da empresa

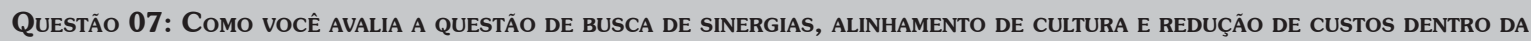
ESTRUTURA INTERNA DA EMPRESA, EM RELAÇÃo AOS SEUS DEPARTAMENTOS E ÁREAS FUNCIONAIS?

Não existe, pois o que vigora é o interesse econômico, financeiro e corporativo E1

É um processo cultural e lento, e o BSC auxilia através da comunicação das estratégias E2

É possível, porém não é fácil, pois é um processo que não pode ser muito "forçado" E3/E5

Ocorre bem aquém do que deveria, existindo muitas falhas e deficiências neste sentido E4/E7

Na teoria é muito mais fácil do que na prática, pois as áreas disputam recursos e interesses E6 
Questão 08: EM RELAÇÃo À QUESTÃo ANTERIOR, DE QUE FORMA O RETORNo FINANCEIRO ADVINDo DESTA BUSCA DE SINERGIA E ALINHAMENTO DE CULTURA PODE SER ENQUADRADO EM ALGUMA PERSPECTIVA DO BSC?

\begin{tabular}{l|l|}
\hline Enquadra-se na perspectiva financeira & Todos menos E3 \\
\hline Enquadra-se nas perspectivas do aprendizado e crescimento e dos processos internos & E3 \\
\hline $\begin{array}{l}\text { Questão 09: Onde se enquadram os ativos intangíveis organizacionais, como pessoas, } \\
\text { práticas, tecnologia e infraestrutura, em relação às perspectivas do BSC? }\end{array}$ & Unanimidade \\
\hline Na perspectiva do aprendizado e crescimento & E1/E2 \\
\hline Na perspectiva dos processos internos & E5 \\
\hline Na perspectiva dos clientes (Marca/Carteira de clientes) & Unanimidade \\
\hline $\begin{array}{l}\text { Questão 10: Onde se enquadram características como desenvolvimento de produtos e serviços } \\
\text { e gestão de demandas e operações, em relação às perspectivas do BSC? }\end{array}$ & E2/E7 \\
\hline Na perspectiva dos processos internos & E3/E5 \\
\hline Na perspectiva dos clientes (Produtos/Serviços inovadores) & \\
\hline Na perspectiva do aprendizado e crescimento &
\end{tabular}

Quadro 4: Resumo da análise das entrevistas com os profissionais da área de estratégia

Fonte: Elaborado pelos autores deste artigo

Após a apresentação e análise dos resultados desta pesquisa, na próxima seção serão demonstradas as conclusões e as considerações finais deste estudo.

\section{Conclusões e Considerações Finais}

O modelo PP apresenta, como principal característica, o foco nos stakeholders organizacionais. Argumenta, inclusive, que sua abrangência dos stakeholders é muito superior à do BSC. Nesse contexto, uma contribuição desta pesquisa foi a percepção de que muitas das características levantadas pelos autores do modelo $P P$, algumas das quais utilizadas em forma de críticas ao $B S C$, em função do não atendimento às mesmas em sua estrutura, na verdade acabaram sendo verificadas como presentes no BSC, a partir dos resultados e da análise realizada na Seção 4 deste estudo. Como aspectos positivos, verificou-se que o BSC pode atender a uma gama de stakeholders maior do que sugerem explicitamente as suas quatro perspectivas originais; que ele incentiva a contribuição dos stakeholders para a organização; que, por meio do modelo a estratégia pode ser comunicada de melhor forma e os processos podem ser bem entendidos; que ele pode auxiliar na difícil busca de sinergia e alinhamento organizacional, englobando o retorno advindo disso, principalmente em sua perspectiva financeira. Também foi verificado que o $B S C$ engloba os ativos intangíveis organizacionais na perspectiva do aprendizado e crescimento e o desenvolvimento de novos produtos e serviços, bem como a gestão de demandas e operações, essencialmente na perspectiva dos processos internos, porém com possibilidade de seu enquadramento nas perspectivas dos clientes e do aprendizado e crescimento.

Em função desses resultados, percebeu-se que é possível um novo olhar no uso do BSC, por meio da consideração de outros stakeholders a partir de sua forma básica, não se atendo apenas naqueles que são evidenciados explicitamente em sua estrutura original. Além disso, este estudo colocou em pauta o modelo $P P$, que é pouco conhecido no Brasil, porém consideravelmente utilizado na Europa. Pelo que se viu, a partir dos resultados desta pesquisa, o $P P$ tem bastante a contribuir em termos de MMDOs, até mesmo como parâmetro de comparação e busca de sinergias ao já consolidado BSC, bem acima de um olhar meramente crítico ao modelo.

Como aspectos que não são contemplados no $B S C$, que podem ser encarados tanto como deficiências quanto como pontos de melhoria, foram identificados: a dificuldade por parte dos especialistas de englobar outros tipos de stakeholders nas perspectivas, um viés de atendimento principalmente às necessidades dos shareholders, e que o desdobramento estratégico sugerido é mais fácil na teoria do que na prática. 
Dessa forma, esta pesquisa atingiu o seu objetivo na medida em que conseguiu responder à questão de pesquisa: quais as contribuições do MMDO PP ao BSC, sob a perspectiva dos stakeholders? Curiosamente, os principais benefícios identificados contrapõem as próprias críticas do $P P$ ao $B S C$, que em grande parte se tornaram questionáveis através da percepção dos entrevistados desta pesquisa, conforme demonstrado na Seção 4.

Embora se tenha buscado realizar um estudo para atender ao objetivo desta pesquisa tomando-se os cuidados metodológicos necessários, foram identificados alguns fatores limitantes às conclusões aqui elencadas, como a pequena quantidade de entrevistados, apesar da relevância qualitativa deles, além da possível subjetividade na análise, em função das percepções e das experiências dos pesquisadores. Como continuidade desta pesquisa sugere-se que esse enfoque nos stakeholders, com a utilização do BSC, seja aplicado às implementações do modelo dentro das organizações, avaliando os resultados deste procedimento através de um enfoque mais quantitativo, em termos de resultados efetivamente alcançados.

\section{REFERÊNCIAS}

BARDIN, L. Análise de conteúdo. Lisboa: Edições 70, 1995.

COOPER, D.; SCHINDLER, P. Método de pesquisa em

administração. 7. ed. Porto Alegre: Bookman, 2003.

COSTA, E. A. Gestão estratégica. São Paulo: Saraiva, 2005.

DEL CARPIO, G. R. A. M.; ROCHA-PINTO, S. R. Fatores críticos para a implementação do BSC: a visão dos consultores organizacionais. In: XXXII ENCONTRO DA ASSOCIAÇÃO NACIONAL DE PÓS-GRADUAÇÃO E PESQUISA EM ADMINISTRAÇÃO (ENANPAD). Rio de Janeiro, Anais... Rio de Janeiro, 2008.

FREEMAN, R. E. Strategic management: a stakeholder approach. Marshfield, Massachusetts: Pitman Publishing Inc, 1984.
GALAS, E. S; PONTE, V. M. R. O BSC e o alinhamento organizacional: um estudo de casos múltiplos. In: XXIV ENCONTRO DA ASSOCIAÇÃO NACIONAL DE PÓSGRADUAÇÃO E PESQUISA EM ADMINISTRAÇÃO (ENANPAD). Brasília, DF, 2005, Anais... Brasília, DF, 2005.

GOMES, G. A. et al. Responsabilidade socioambiental corporativa e indicador de maturidade mediando desempenho estratégico para as organizações. Revista de Ciências da Administração, Florianópolis, v. 12, n. 26, p. 244-269, jan.-abr. 2010.

KAPLAN, R. S.; NORTON, D. P. The BSC: translating strategy into action. Boston: Harvard Business School Press, 1996.

KAPLAN, R. S.; NORTON, D. P. A estratégia em ação: BSC. 7. ed. Rio de Janeiro: Campus, 1997.

\section{KAPLAN, R. S.; NORTON, D. P. Organização}

orientada para a estratégia: como as empresas que adotam o BSC prosperam no novo ambiente de negócios. Rio de Janeiro: Campus, 2000.

KAPLAN, R. S.; NORTON, D. P. Mapas estratégicos - BSC: convertendo ativos intangíveis em resultados tangíveis. 6. ed. Rio de Janeiro: Elsevier, 2004.

MARCONI, M. A.; LAKATOS, E. M. Fundamentos de metodologia científica. 5. ed. São Paulo: Atlas, 2003. p. 311.

MARINHO, S. V.; CAMPOS, L. M. S.; SELIG, P. M. Uma Proposta de Sistemática para Operacionalização da Estratégia utilizando o BSC. In: XXXI ENCONTRO DA ASSOCIAÇÃO NACIONAL DE PÓS-GRADUAÇÃO E PESQUISA EM ADMINISTRAÇÃO (ENANPAD). Rio de Janeiro, 2007, Anais... Rio de Janeiro, 2007.

MATTAR, F. N. Pesquisas de marketing: metodologia, planejamento, execução e análise. São Paulo: Atlas, 1992.

MINTZBERT, H.; AHLSTRAND, B.; LAMPEL, J. Safári

de Estratégia: um roteiro pela selva do planejamento estratégico. Porto Alegre: Bookman, 2000.

MINTZBERG, H; QUINN, J. B. O processo da estratégia. 3. ed. Porto Alegre: Bookman, 2001. 
NEELY, A.; GREGORY, M. Performance measurement system design. International Journal of Operations \& Producy Management, Cambridge, v. 15, 1995.

NEELY, A.; ADAMS, C.; CROWE, P. The Performance Prism in Practice. Measuring Business Excellence, n. 5, v. 2 p. 6-12, 2001.

NEELY, A.; ADAMS, C.; KENNERLY, M. The

Performance Prism: the scorecard for measuring and managing business success. London, Prentice Hall. 2002.

NORREKLIT, $\mathrm{H}$. The balance on the BSC - a critical analysis of some of its assumptions. Management Accounting Research, v. 11, n. 1, p. 65-88, Academic Press. 2000.

OLIVEIRA, P. H.; GONÇALVES, C. A.; DE PAULA, E. A. M. Visão Baseada em Recursos da Empresa, Inteligência Competitiva e Balanced Scorecard: em Busca da Vantagem Competitiva Sustentável. Revista de Ciências da Administração, Florianópolis, v. 12, n. 28, p. 60-82, set.-dez. 2010.

SAMPIERI, R. H.; COLLADO, C. F; LUCIO, P. B. Metodología de la investigación. México: McGrawHill, 1991.

SCHNEIDERMAN, A. M. Why BSC fail. Journal of Strategic Performance Measurement, Special Edition. p. 6-11. 1999.

\section{SOARES JÚNIOR, H.; PROCHNIK, V. Experiências} comparadas de implantação do BSC no Brasil. [2004]. Disponível em: <http://ww2.ie.ufrj.br/ cadeiasprodutivas/pdfs/implantacao_do_balanced_ scorecard_no_brasil.pdf $>$. Acesso em: 17 out. 2011.

SOUZA, B. B. P.; FERREIRA, B. P.; GOSLING, M. Modelagem matemática do BSC - BSC: adequações aos problemas de convergência e de co-integração nos indicadores desse sistema gerencial. In: XXXII ENCONTRO DA ASSOCIAÇÃO NACIONAL DE PÓSGRADUAÇÃO E PESQUISA EM ADMINISTRAÇÃO (ENANPAD). Rio de Janeiro, 2008, Anais... Rio de Janeiro, 2008.
THOMPSON, J. K.; WARTICK, S. L.; SMITH, H. L.

Integrating Corporate Social Performance and stakeholder management: implications for a research agenda in small business. Research in Corporate Social Performance and Policy, v. 12, p. 207-230, 1991. 